\title{
VIII \\ SERVIÇO SOCIAL E MOVIMENTOS SOCIAIS: \\ DESAFIOS EM TEMPOS DE RECRUDESCIMENTO DO \\ CONSERVADORISMO*
}

Sabrina dos Santos Dias ${ }^{1}$

\section{INTRODUÇÃO}

A articulação do Serviço Social com movimentos sociais constitui uma necessidade, permeada de desafios, desde a conformação do atual Projeto Ético-Político ${ }^{2}$ da profissão. O novo perfil profissional apontado e os compromissos éticos estabelecidos, em especial a partir do movimento de reconceituação e a aproxima à teoria crítica, indicam, necessariamente, uma vinculação com as lutas da classe trabalhadora. Isso não significa, no entanto, que esta seja uma realidade vivenciada de forma ampla no âmbito profissional e da formação. Desse modo, esse é ainda um desafio, e uma tarefa, para a formação e ação profissional.

A história de desenvolvimento do capitalismo, da burguesia e do Estado no Brasil é demarcada pelas feições conservadoras e autoritárias, derivadas de um sistema tardio e dependente, o que, por si só, impõe contradições à organização dos trabalhadores. Ainda assim, ao analisar a formação brasileira, desde sua gênese, há processos de resistência dos segmentos de classes exploradas, que são fundamentais para a construção das conquistas sociais existentes- ainda que, atualmente, em processo de desmonte. Ou seja, apesar das condições ad-

*DOI - 10.29388/978-65-86678-35-2-0-f.179-196

1 Assistente social, Mestranda do Programa de Pós Graduação em Serviço Social e Desenvolvimento Regional/ UFF e Pesquisadora do Núcleo de Estudos e Pesquisas sobre Favelas e Espaços Populares.

${ }^{2}$ Entende-se como o projeto profissional hegemônico o chamado Projeto Ético-Político do Serviço Social (PEP) brasileiro, construído a partir da década de 1980. Este representa a configuração de um novo perfil do Serviço Social e estabelece vínculo ao projeto societário da classe trabalhadora e suas lutas pela emancipação humana (NETTO, 1999). 
versas das lutas sociais, marcam a história do país e de organização da classe trabalhadora. Entretanto, como uma especificidade de uma nação da periferia do capitalismo internacional como a brasileira, as respostas dadas pelo Estado e pela burguesia, absorvendo parte das demandas dos trabalhadores e as ressignificando, atuaram historicamente como fatores limitantes aos processos organizativos da classe.

Com a crise do capital que tem início na década de 1970, e que se agrava de sobremaneira a partir da década de 1990, são impostas contrarreformas ao Estado, a partir das diretrizes do Consenso de Washington de 1989 e do projeto neoliberal, que fortalece o conservadorismo e o autoritarismo. Especialmente nos últimos anos ${ }^{3}$, há intensificação da ofensiva à organização dos trabalhadores, ampliando, assim, os desafios aos movimentos sociais, e a articulação do Serviço Social a esses processos.

A aproximação aos movimentos sociais, tanto no fazer profissional como na formação, é hoje uma das questões centrais postas para a categoria. $\mathrm{O}$ horizonte é árido para as organizações da classe trabalhadora, assim como para as universidades públicas - espaços privilegiados para essa imbricação. Contudo, contraditoriamente, exatamente pela ampliação dos desafios e ataques das classes dominantes, é que a busca por essa vinculação se faz ainda mais necessária. Para os assistentes sociais, estar vinculado aos movimentos sociais é crucial tanto para manter vivo o Projeto Ético-Político, quanto enquanto parte da classe trabalhadora, diretamente impactada com os avanços do conservadorismo.

Assim, a primeira parte deste texto abordará aspectos centrais da crise do capital e da contrarreforma do Estado, bem como a discussão sobre conservadorismo, aspecto intrínseco a formação social brasileira, e a relação com o Serviço Social. Em um segundo momento, será abordada a relação do Projeto Ético-Político do Serviço Social e os movimentos sociais, indicando os principais desafios a essa aproximação. Como espaço fértil de possibilidades de fomento a essa articulação serão indicados aspectos acerca da formação em Serviço Social.

\footnotetext{
3 As eleições de 2018 no Brasil podem ser consideradas espectro mais marcante desse processo, entretanto, deve-se indicar que o fortalecimento recente do conservadorismo no Brasil iniciou-se anos antes, após as manifestações de junho de 2013. A eleição de um governo de extrema direita apenas tornou-se possível por ter havido um aprofundamento social de pautas sociais, políticas e econômicas simpáticas a essa vertente.
} 


\section{1- CRISE DO CAPITAL, AVANÇO DO CONSERVADORISMO E SERVIÇO SOCIAL}

No Brasil, principalmente a partir da década de 1990 há o aprofundamento da crise cíclica do capital, que mundialmente teve seu início na década de 1970. Passa a ocorrer também a implantação e espraiamento do neoliberalismo, que gesta transformações em todas as esferas sociais. Uma das características dessa nova fase do capitalismo é o recrudescimento do conservadorismo, em distintos âmbitos da vida social. Não obstante, esse período é demarcado também pelas lutas sociais, provenientes dos movimentos da década de 1980 e da construção da Constituição Federal de 1988 (CF/88).

O ideário neoliberal ${ }^{4}$ e a reestruturação produtiva baseada em modelo de acumulação flexível, como aponta Imbiriba (2016), engendra uma série de reformas pró- mercado e o espraiamento destas orientações para os países da periferia, tendo como expressão desse processo o chamado Consenso de Washington de 1989. Este fora realizado, principalmente, pelos organismos multilaterais como a Organização das Nações Unidas (UNESCO) e o Fundo Monetário Internacional (FMI), e condicionaram a concessão de auxílios financeiros a esses países à aceitação e implantação da agenda neoliberal, baseado nas ideias de livre mercado e reorganização de intervenção na esfera social. $\mathrm{Na}$ esfera produtiva, a acumulação flexível estabelece processo de flexibilização e precarização dos processos de trabalho, intensificando a retirada de direitos trabalhistas no mundo todo e intensificando a articulação entre o moderno e o arcaico com a conjugação de diferentes formas de exploração e aviltamento da força de trabalho.

As medidas adotadas pelo neoliberalismo, nos países centrais pós 1970 e no Brasil após 1990, significaram retrocessos para a classe trabalhadora e seus processos organizativos. Tais medidas foram difundidas amplamente como sen-

\footnotetext{
${ }^{4} \mathrm{O}$ neoliberalismo consiste na resposta do capital a mais uma de suas crises cíclicas. A sociabilidade neoliberal acarreta modificações nas esferas produtivas, políticas e sociais. O neoliberalismo significa aprofundamento de uma sociabilidade em que valores de competitividade e individualismo reverberam-se. Ver mais em: ANTUNES, R. Dimensões da crise e metamorfoses do mundo do trabalho. Serviço Social e Sociedade, São Paulo, ano XVIII, n. 50, 1996.
} 
do reformas fundamentais para reestruturar a sociedade da crise. Entretanto, de acordo com Behring e Boschetti (2011):

Embora, o termo reforma tenha sido largamente utilizado pelo projeto em curso no país nos anos 1990 para se autodesignar, partimos da perspectiva de que se esteve diante de uma apropriação indébita e fortemente ideológica da ideia reformista, a qual é destituída de seu conteúdo redistributivo de viés social democrata, sendo submetida ao seu uso pragmático, como se qualquer mudança significasse uma reforma, não importando seu sentido, suas consequências sociais e sua direção sócia histórica. (BEHRING; BOSCHETT'TI, 2011, p. 149)

Tais alterações denominadas reformas possuem caráter reacionário e, portanto, o uso deste nome é indevido. Reformas são, pois, conquistas da classe trabalhadora, como os direitos sociais e políticas. O neoliberalismo significa, deste modo, o aprofundamento de uma sociabilidade em que valores de competitividade e individualismo reverberam-se.

O contexto neoliberal no Brasil apresenta também a acentuação da perspectiva autoritária do Estado e da burguesia. Ianni (1984) explicita que a formação social brasileira teve sempre como característica o autoritarismo e arbítrio do Estado e das classes dominantes. O autor indica que na história do Brasil e marcada por uma contrarrevolução burguesa permanente, ou seja, uma ação autoritária permanente desses setores em uma antecipação, e coerção, de movimentos populares que poderiam ameaçar o status quo. "Todas as formas históricas do Estado, desde a Independência até o presente, denotam a continuidade e reiteração das soluções autoritárias, de cima para baixo, pelo alto, organizando o Estado segundo os interesses oligárquicos, burgueses, imperialistas.” (IANNI, 1984, p. 11) Períodos de democracia no país são frequentemente interrompidos por intervenções autoritárias, o que é emblemático na conjuntura política atual.

Seja impondo-se pela violência, seja antecipando-se na adoção de medidas paliativas, seja cooptando lideranças e organizações, com frequência as classes e frações das classes dominantes impõem-se aos grupos e classes subordinados, na cidade e no campo. De modo algum, como salienta o autor supracitado, esse processo de autoritarismo representa uma organização enfraquecida dos trabalhadores, mas ao contrário, um Estado e classes dominantes duramen- 
te opressores. Esta é, pois, uma das razões para que esforços sejam direcionados na criação de estratégias de resistência e organização, que possam responder a realidade de repressão.

Cabe aqui ressaltar a concepção de Estado que se parte nesse trabalho. Como já apontado, entende-se Estado de forma oposta a visão se uma superestrutura imparcial às classes. O Estado para o marxismo, é compreendido a partir da materialidade, opondo-se ao idealismo. O conjunto das relações de produção é a base econômica da sociedade, e sobre esta e a partir desta se eleva uma superestrutura jurídica, política e de consciência social, como aponta Marx (2007) onde pode-se entender as representações do Estado. O Estado classista tem essencial função, como forma de manutenção do status quo, podendo, em alguns momentos absorver parcialmente demandas dos trabalhadores, sem, no entanto, perder suas características basilares, como afirmava Marx, como comitê da burguesia. O autor italiano Antonio Gramsci fornece orientações importantes para conceber o Estado, principalmente em fase de alta complexificação da sociedade. Para Gramsci, como aponta Coutinho (1996), o Estado é conformado pela sociedade política, composta pelos aparelhos coercitivos, com monopólio do uso legal da violência, para exercer a dominação; e pela sociedade civil, enquanto conjunto das instituições responsável pelos interesses das classes, de maneira não homogênea e sendo lócus das lutas sociais (aparelhos privados de hegemonia) para exercício da direção ideológica. Nesta perspectiva, o Estado não é um ente em si, mas expressão das disputas entre as classes. Isso significa que, ainda que, a classe dominante possua, em geral, a hegemonia no Estado, ele não é monolítico.

Essa conjuntura traz consigo o recrudescimento do conservadorismo, que está intimamente ligado a esse processo de reformulação do capital e do Estado. O conservadorismo deve-se destacar, não é forjado pelo neoliberalismo, apenas aprofundado e colocado em novas roupagens. Ele é parte do modo de produção capitalista, é gestado pelo capital, e atende a seus interesses. Em determinados momentos históricos, em decorrência dos avanços das lutas dos trabalhadores, o conservadorismo é relativamente ocultado, em outros, como o atual, há sua explicitação. Netto (2011) aponta que a partir da década de 1970 há um crescimento acentuado do conservadorismo, relacionado ao neoliberalis- 
mo, com a particularidade de que esse pensamento conservador busca esconder-se, através de narrativas que se propõe progressistas.

De acordo com Netto (2011), o pensamento conservador é historicamente determinado, situado a sociabilidade capitalista. No período de Revolução Burguesa e constituição do capitalismo é que surge o pensamento conservador, neste momento possuía um caráter de anticapitalismo romântico, na medida em que expressava os interesses dos setores dominantes do Antigo Regime. Possuía, portanto, um caráter de restauração. Na medida em que a socieda de burguesa se institui efetivamente e este cenário se apresenta como irreversível, a face do conservadorismo se altera, porque o papel da burguesia se transforma. De uma classe revolucionária a burguesia se transforma em classe dominante, e nesse momento seus ideais progressistas transformam-se em particularistas, como destaca a autora. A partir de 1830 inicia-se ataque da classe dominante a qualquer questionamento da ordem, o que tem seu ápice em 1848 com as revoltas dos trabalhadores. Conservadorismo deixa então de possuir um caráter de restauração ao Antigo Regime, para buscar a manutenção da nova sociabilidade, sob o controle da burguesia. No desenvolver do capitalismo, o conservadorismo é traço fundante, e isso se reverbera em todas as esferas da vida social, e incluem-se aí as profissões.

O Serviço Social se gesta intimamente relacionado a ordem monopólica burguesa, e deste modo também ao conservadorismo. Compreender as determinações da formação do Serviço Social é essencial para não cair na leitura endógena. Iamamoto e Carvalho (2013) apontam que para compreender o significado social da profissão deve-se analisá-la historicamente situada, “[...] configurada como um tipo de especialização do trabalho peculiar à sociedade industrial." (IAMAMOTO; CARVALHO, 2013, p. 77) A dinâmica das relações sociais entre as classes influi no Serviço Social, e assim, a intervenção profissional está sempre polarizada pelos interesses das classes, como apontam os autores. Necessariamente, a atuação profissional vai fortalecer um dos dois polos, e tem tido uma tendência histórica a estar imbricada aos interesses dominantes. Todavia, o reconhecimento disto, possibilita a criação de uma intervenção voltada aos interesses dos trabalhadores.

De acordo com Adriano e Guazzelli (2016), a reatualização do conservadorismo na sociedade burguesa atual tem ramificações no interior das profis - 
sões, apresentado como a pós-modernidade. No Serviço Social, esses desdobramentos impactam diretamente na forma de análise da sociedade e da questão social. Realiza-se uma fragmentação, que a retira da totalidade social, e passa a "tratar" separadamente suas expressões. Em inversão de sentido, atribui-se aos indivíduos a causa das mazelas sociais. Oculta-se que, como ressalta Iamamoto (2001):

A questão social diz respeito ao conjunto das expressões das desigualdades sociais engendradas na sociedade capitalista madura, impensáveis sem a intermediação do Estado. Tem sua gênese no caráter coletivo da produção, contraposto à apropriação privada da própria atividade humana- o trabalho-, das condições necessárias à sua realização, assim como de seus frutos. É indissociável da emergência do "trabalhador livre", que depende da venda da sua força de trabalho como meio de satisfação de suas necessidades vitais. A questão social expressa, portanto, disparidades econômicas, políticas e culturais das classes sociais, mediatizadas por relações de gênero, características étnico-raciais e formações regionais, colocando em causa as relações entre amplos segmentos da sociedade civil e o poder estatal. (IAMAMOTO, 2001, p. 16-17)

Esse cenário político, econômico e social adverso para a classe trabalhadora, e que impacta no interior das profissões, pressiona a categoria de assistentes sociais para um fazer profissional oposto aos compromissos do Projeto Ético-político. Apesar de gestado pelo conservadorismo, no seu desenvolver histórico, a categoria realizou uma inversão de paradigma, que a colocou alinhada aos interesses da classe trabalhadora, ainda que, inevitavelmente, também atendendo demandas das instituições burguesas. Todavia, hegemonicamente foi indicado um compromisso com a superação desta ordem societária, que significou um salto qualitativo para a profissão. Defender essas conquistas, frente ao avanço do conservadorismo, também no interior da profissão, que, obviamente, não é monolítica, demanda estratégias de alinhamento real a classe trabalhadora. Essas, sem dúvida, podem ocorrer no interior das instituições, mas é imprescindível que as ultrapassem, em caminho aos movimentos sociais. 


\section{2- PROJETO ÉTICO-POLÍTICO E MOVIMENTOS SOCIAIS: DE- SAFIOS E POSSIBILIDADES}

Algo primordial ao tratar de Projeto Ético-Político é destacar que se trata de uma construção coletiva e algo mutável. Ele é reflexo das relações sociais no tempo histórico, da conjuntura macrossocietária, das lutas sociais, e das disputas no interior da categoria profissional. Entretanto, não raro, ao falar do projeto profissional, apontam-se suas características, quase de maneira mecânica, como se fosse algo imóvel, dado e terminado, de fato, não é sendo fundamental destacar incansavelmente este aspecto. $\mathrm{O}$ enraizamento do atual projeto profissional do Serviço Social demanda esforços da categoria, para mantê-lo como hegemônico, visto que está em disputa.

A configuração do Projeto Ético-Político depende da direção hegemônica da profissão, que hoje é de caráter progressista, vinculada à crítica radical ao capitalismo e luta pela construção de uma nova ordem societária. Entretanto, a história da profissão remete a outras vinculações. Ou seja, o Serviço Social brasileiro nem sempre esteve atrelado a uma leitura crítica do modo de produção capitalista e compromissado com a superação desta ordem. A profissão surge no Brasil na década de 1930, permeada por valores humanista-cristãos, de propagação do pensamento social católico. Nas décadas seguintes, o Serviço Social se aproxima do pensamento positivista, que apesar de oposto a concepção de realidade adotada hoje, que é o marxismo, em alguma medida significou para os profissionais a aproximação com as ciências sociais e o afastamento da influência católica. Somente a partir do final da década de 1950 e início do decênio seguinte é que tal perspectiva teórica e de atuação começa a ser questionada pela categoria profissional, dando início ao chamado Movimento de Reconceituação do Serviço Social.

O Projeto Ético-Político do Serviço Social, de acordo com Netto (1999), tem seu processo de construção iniciado na passagem das décadas de 1970 para 1980, mas sua consolidação como hegemônico pode ser relacionado à década de 1990. O autor explicita que um projeto profissional está necessariamente atrelado a um projeto societário, e que em uma sociedade como a capitalista, estará essencialmente relacionado a uma classe social. Destarte, o projeto do Serviço Social, configurou-se hegemonicamente atrelado a classe trabalha- 
dora e, portanto, o compromisso com a construção de uma nova ordem societária. "Os projetos profissionais apresentam a autoimagem de uma profissão, elegem os valores que a legitimam socialmente, delimitam e priorizam seus objetivos [...]" (NETTO, 1999, p. 4) e são construídos coletivamente, no Brasil, o autor identifica esse sujeito coletivo como sendo o sistema CFESS/CRESS, a ENESSO, a ABEPSS e os sindicatos e associações.

Pode-se identificar como instrumentos de materialização do Projeto Ético- Político do Serviço Social: o Código de Ética Profissional, a Lei de Regulamentação da Profissão, as Diretrizes Curriculares e as entidades CFESS/ CRESS, ABEPSS e ENESSO. Cada um destes possui fundamental importância para dar capilaridade ao projeto profissional.

Como já indicado, os projetos profissionais não são estáticos e perenes, mas estão em constante movimento. Deste modo, esforços para materializá-lo e para legitimá-lo na sociedade e na própria categoria são essenciais. A categoria profissional é arena de disputas, um projeto ser hegemônico não significa ser o único.

Os projetos profissionais também são estruturas dinâmicas, respondendo às alterações no sistema de necessidades sociais sobre o qual a profissão opera, às transformações econômicas, históricas e culturais, ao desenvolvimento teórico e prático da própria profissão e, ademais, às mudanças na composição social do corpo profissional. Por tudo isto, os projetos profissionais igualmente se renovam, se modifica. (NETTO, 1999, p. 4 5)

O atual projeto profissional tem como marco a ruptura com conservadorismo e vínculo real com a classe trabalhadora e princípios como o compromisso com a construção de uma nova ordem societária, a busca pela equidade e justiça social, compromisso com a democracia e negação de todas as formas de preconceito, além de ter na liberdade seu valor ético central. Entretanto, projetos conservadores disputam a direção da profissão.

A sobrevivência e fortalecimento deste projeto, segundo Netto (1999), depende tanto da articulação interna da categoria pera lhe dar capilaridade, quanto do fortalecimento da luta geral dos trabalhadores. Desse modo, é essencial que os assistentes sociais estejam imbricados as lutas dos trabalhadores, e 
ao mesmo tempo, construam internamente maneiras de fortalecer o Projeto Ético-Político.

Está colocada a possibilidade de retrocessos no interior do Serviço Social, pois, o movimento da sociedade se reflete e também se encontra dentro do Serviço Social, e assim, as disputas estão presentes no projeto profissional. Deste modo, é impreterível a construção de processos de resistência e defesa do projeto profissional no interior da profissão. De acordo com Duriguetto (2014), uma estratégia do Serviço Social para enfrentar esta ofensiva do capital a classe trabalhadora seria exatamente as intervenções nos processos organizativos e de mobilização popular. Esse tipo de atuação profissional possibilita revigorar o projeto ético-político, mas também a criação de novas formas do próprio fazer profissional.

É importante ressaltar que inúmeras são as concepções de movimentos sociais, e que, inclusive perspectivas conservadoras as possuem. Mesmo no interior da perspectiva crítica existem divergências, dada a amplitude e complexidade que compreende a temática. Santos (2008) aponta duas perspectivas acerca de movimentos a partir de Maria G. Gohn e Ana Maria Doimo[A2], que se opõe em um ponto central: a primeira defende que a transformação é possível se ser realizada pela conquista do aparelho estatal, enquanto que a segunda não acredita nesta proposição. Acredita-se aqui que a conquista de setores do aparelho estatal pode ser muito estratégica para luta dos trabalhadores, entretanto, não deve se encerrar nisto. O Estado, enquanto hegemonizado pelos interesses da burguesia, jamais poderá proporcionar a emancipação.

Deste modo, o objetivo central dos movimentos sociais, e que deve haver a articulação do Serviço Social, é a superação do modo de produção capitalista. Significa atribuir "ao capitalismo a origem dos problemas e procuram desenvolver estratégias e práticas de luta que modifiquem as estruturas dessa sociedade.” (SANTOS, 2008, p.19) Entretanto, não se deve restringir sua luta no lema "contradição capital/trabalho", apesar de sua centralidade. A correlação de forças entre as classes sociais é mais complexa, e engendra outras questões como questão de gênero e étnico-racial. Todavia, o cerne das contradições e enfoque da luta pode ser relacionado ao capitalismo.

Mattos (2017) aponta que apesar de não ser possível uma definição consensual sobre movimentos sociais, pode-se indicar que todos organizam co- 
letivamente algum conflito social. Contudo, os movimentos podem ser gerados de ambos os lados da disputa. Ele alerta, desse modo, que há os movimentos realizados pelas classes exploradas e pelas classes exploradoras. Não necessariamente um movimento social é progressista. Por isso, é fundamental ao falar de movimentos sociais, evidenciar a partir de qual perspectiva se parte.

Farage (2014) elenca características importantes para pensar movimentos sociais a partir da teoria crítica, e que representam a perspectiva aqui adotada. Dentre elas aponta-se: 1 - surgirem a partir de demandas específicas e fora do espaço produtivo formal; 2- possuir traços da luta classista; 3- autônomos em relação ao governo; 4 - realização de ações diretas e; 5 - possui norte anticapitalista, apesar de estabelecerem diálogo com o poder público.

Assim sendo, o vínculo com os movimentos sociais, de norte anticapitalista, possibilita estar realmente em alinhamento com os interesses da classe trabalhadora. $\mathrm{O}$ assistente social possui necessariamente em sua atuação uma face pedagógica, ou formadora da cultura, que em sentido gramsciano, significa a incisão no modo de pensar e agir dos sujeitos, como apontam Abreu, Cardoso e Lopes (2014). Tal pedagogia pode estar relacionada ao controle social ou ter caráter emancipatório. A pedagogia emancipatória, apresenta uma estratégia para a sustentação do Projeto Ético- Político, uma vez que possibilita uma atuação profissional está para além das demandas institucionais, com vistas a fortalecer as lutas dos trabalhadores. As experiências com movimentos sociais são de suma importância para dar sentido ao projeto profissional, bem como para ratificar o compromisso com a superação deste modo de produção.

É compreensível que o assistente social enquanto trabalhador tenha majoritária inserção institucional. Contudo, limitar-se a essa esfera é uma questão a ser problematizada. A aproximação real com as lutas da classe trabalhadora é fundamental, pois, em dois sentidos: para fortalecer o projeto ético-político profissional que tem como pressuposto esta articulação; e pelos ganhos da classe trabalhadora em si, pois, é frequente que os assistentes sociais tratem a classe trabalhadora com externalidade, como se não fizesse parte dela, sinaliza Raichelis (2011).

A inserção real de assistentes sociais nesses espaços, assim como maior aproximação teórica é perpassada por desafios, e apenas coletivamente é possível criar estratégias que possibilitem essa aproximação. Desde o contexto de 
precarização do mundo do trabalho e desemprego, até sucateamento das universidades e repressão aos movimentos sociais constituem esses desafios, mas, ainda assim, a partir deles, faz-se necessários moldar caminhos coletivos.

\section{1- A tarefa da formação profissional}

$\mathrm{Na}$ perspectiva de que o projeto ético-político estabelece resistência ao projeto hegemônico do capital, torna-se primordial buscar estratégias para fortalecimento daquele, barrando as ondas conservadoras ou reacionárias colocadas em disputa no interior da categoria, fruto das contradições postas nas relações sociais, primando pelo comprometimento com a conquista de direitos e articulação com as formas de resistências da classe trabalhadora. Para tal, a formação profissional é lócus privilegiado para fomentar a articulação do Serviço Social com os movimentos sociais. A ampliação de experiências nestes espaços, assim como uma maior implicação com os debates sobre as lutas sociais propicia significa, além do fortalecimento do Projeto Ético-Político, a reafirmação do projeto de educação que o Serviço Social defende, que está necessariamente imbricado com as demandas coletivas dos trabalhadores, em desfavor a perspectiva elitista de universidade, que lamentavelmente ainda é majoritária no Brasil.

Para fomento de estratégias e articulações que materializem o projeto ético- político na atuação profissional a formação tem papel fundamental. As sim sendo, é importante questionar se a formação profissional, apesar de sua direção crítica e progressista, proporciona a necessária aproximação dos(as) discentes de Serviço Social com o debate de movimentos sociais e organização coletiva da classe trabalhadora e se proporciona experiências profissionais nestes espaços. ${ }^{5}$

Defende-se que Serviço Social pode apresentar contribuições para os movimentos sociais, mas, sem dúvidas tem muito a aprender nesta área. A inserção de assistentes sociais nos movimentos sociais possibilitaria visualizar a

\footnotetext{
${ }^{5}$ Entende-se que o contexto de sucateamento das universidades públicas e ampliação da mercantilização do ensino superior, com ênfase no ensino a distância, são fatores que comprometem esse ensino articulado aos movimentos sociais. Cabe, em estudo específico, problematizar, em grau mais acentuado os desafios para pensar essa aproximação nesses contextos.
} 
intervenção profissional de maneira inédita e, assim, pensá-la de maneira crítica, problematizando o caráter histórico da atuação profissional, como sinaliza Marro (2014).

As Diretrizes Curriculares da ABEPSS de 1996, instrumento importante para formação profissional, trazem como alguns de seus princípios a opção por uma teoria social crítica, com apreensão da categoria totalidade social; a flexibilidade na organização dos currículos; a superação da fragmentação dos conteúdos e a indissociabilidade entre ensino, pesquisa e extensão. Trouxe, ainda, uma nova lógica de organização curricular, referenciando a categoria trabalho como central nesta organização. Divide as diretrizes em três núcleos de fundamentação, são eles: 1- Núcleo de fundamentos teórico- metodológicos da vida social; 2-Núcleo de fundamentos da particularidade da formação sócio histórica da sociedade brasileira e 3- Núcleo de fundamentos do trabalho profissional. Entretanto, apesar das Diretrizes Curriculares ratificarem ao longo de todo o seu texto os compromissos apresentados no Código de Ética pode-se perceber uma lacuna preocupante. $\mathrm{Na}$ indicação das matérias básicas não aparecem citadas como tais, explicitamente, as questões como de gênero e raça e a temática dos movimentos sociais. Cita-se apenas brevemente dentro da matéria de Acumulação Capitalista e Desigualdades Sociais. Dada a relevância, deveria ter sido atribuída maior ênfase, inclusive de maneira transversal em todos os núcleos de fundamentação.

O NEPFE ${ }^{6}$ realizou uma pesquisa voltada para a relação entre a formação profissional e os movimentos sociais, e parte dela consistiu em analisar os Projetos Pedagógicos das universidades públicas vinculadas a $\mathrm{ABEPSS}^{7}$, com vistas a perceber de que forma essa temática aparecia. Um dos dados obtidos relaciona-se ao número de disciplinas encontradas que abordam os movimentos sociais. Foram analisadas 22 universidades, e no total foram encontradas 31 disciplinas (obrigatórias e eletivas/optativas) que citavam em suas ementas "movimentos sociais", entretanto, na análise qualitativa, em apenas 18 delas a temática possuía centralidade.

\footnotetext{
${ }^{6}$ Núcleo de Estudos e Pesquisas sobre Favelas e Espaços Populares (NEPFE)-UFFcoordenado pela Prof. Dra. Eblin Farage

${ }^{7}$ Associação Brasileira de Ensino e Pesquisa em Serviço Social
} 
Esses são indicativos de que a discussão de movimentos sociais não é transversal na formação de Serviço Social. Obviamente, que esses dados foram tirados de uma amostra para pesquisa, e que a realidade possui maior complexidade. Ressalta-se que, nas universidades, os projetos de extensão são os espaços de maior aproximação com os movimentos sociais, entretanto, não é a totalidade do corpo discente que acessa esses espaços. A pesquisa realizada, além do dado aqui relatado, evidenciou o afastamento da discussão de movimentos sociais nos cursos de Serviço Social. O questionamento gerado é: se nas universidades públicas vinculadas a Abepss, em que há maior possibilidade e autonomia para relação com movimentos sociais isso não ocorre, qual é o cenário nas universidades privadas e cursos a distância? Se esse debate não é transversal na formação, como indicar a necessidade real de vinculação aos movimentos sociais aos assistentes sociais na prática profissional?

\section{3- CONSIDERAÇÕES FINAIS}

A exposição realizada aqui teve como objetivo apontar alguns pontos relevantes para pensar a relação do Serviço Social com os movimentos sociais, em tempos adversos. O NEPFE tem realizado pesquisas com esse enfoque desde 2014, com as ocupações do Movimento dos Trabalhadores Sem-Teto em São Gonçalo e Niterói/ RJ, a partir da apreensão de que essa aproximação era algo inédito para a maioria dos pesquisadores, discentes e assistentes sociais formados. A partir disso, percebeu-se que era imperativo trazer à pauta das discussões a importância da inserção nos movimentos sociais. Nos anos seguintes a conjuntura política do país tornou-se adversa a organização política dos trabalhadores, o que evidenciou que essas dificuldades se ampliariam.

A tarefa de aproximação aos movimentos sociais como forma de defesa do projeto profissional e como defesa dos interesses da classe trabalhadora, enquanto parte dela, é permeada por obstáculos, intensificados pelo avanço da extrema direita no Brasil. Mas de nenhum modo, isso significa a impossibilidade dessa relação.

Contextos assim tendem a levar ao fatalismo, que se reverbera no interior das profissões e nas organizações dos trabalhadores. A contradição posta é que, o fortalecimento dos processos organizativos, mesmo nesta conjuntura, é 
que pode possibilitar combater o fatalismo. No caminhar e construir das lutas e que maiores possibilidades de organização irão se gestar.

Sem dúvida, tornou-se ainda mais desafiador pensar possibilidades de aproximação com os movimentos sociais no cotidiano profissional. Majoritariamente os assistentes sociais atuam em equipamentos do Estado, que endossa e é endossado pelo conservadorismo, e assim, poda novas possibilidades do trabalho. Nas universidades, com o sucateamento e mercantilização, a imbricação nesse sentido tende a ser secundarizada. Todos os obstáculos são reais, e estão postos para que a categoria lhes dê respostas coletivas. Estas podem ser de cooptação aos interesses dominantes, ou de resistência e defesa do perfil profissional construído.

Não é possível apresentar aqui respostas conclusas acerca de caminhos a serem realizados pela categoria, pois apenas coletivamente é possível. Pode-se apenas indicar que é necessário avançar do discurso de articulação aos movimentos sociais. Está colocada a possibilidade de que a hegemonia crítica do Serviço Social seja substituída por perspectivas declaradamente conservadoras.

\section{REFERÊNCIAS}

ABEPSS. Diretrizes Curriculares ABEPSS - Brasília, 1996. ABEPSS. Política Nacional de Estágio. Brasília, 2010. Disponível em: < http://www.abepss.org.br/diretrizes-curriculares-da-abepss-10 > . Acesso em: 12 set. 2020. ABREU, M. M.; CARDOSO, F. G.; LOPES, J. B. O caráter pedagógico da intervenção profissional e sua relação com as lutas sociais. In: ABRAMIDES, M.B.C e DURIGUETTO, M.L (orgs) Movimentos Sociais e Serviço Social: uma relação necessária. São Paulo: Cortez, 2014, p. 195-213.

ADRIANO, A. L.; GUAZZELLI, A. Formação Profissional em Serviço Social: Fundamentos e Desafios Ético-Políticos. Temporalis, Brasília, ano 16, n. 31, p. 237-260,jan-jun. 2016.

BEHRING, E. R.; BOSCHETTI, I. Política social: fundamentos e história. 9. ed. São Paulo: Cortez, 2011. 
BRASIL. Constituição Federal (1988). Constituição da República Federativa do Brasil. Brasília, DF: Senado, 1988.

COUTINHO, C. N. Marxismo e Política: a dualidade de Poderes e outros ensaios. 2. ed. São Paulo: Cortez, 1996.

DURIGUETTO, M. L. Movimentos Sociais e Serviço Social no Brasil pós 1990. In: ABRAMIDES, M.B.C e DURIGUETTTO, M.L (orgs) Movimentos Sociais e Serviço Social: uma relação necessária. São Paulo: Cortez, 2014, p.177-194.

FARAGE, E. J. Experiências Profissionais do Serviço Social nos Movimentos Sociais Urbanos. In: ABRAMIDES, M.B.C e DURIGUETTO, M.L (orgs) Movimentos Sociais e Serviço Social: uma relação necessária. SP: Cortez, 2014, p.245-262.

IAMAMOTO, M. A Questão Social no Capitalismo. Revista Temporalis, Brasília, ano II, n. 3, janeiro-junho de 2001, p. 1-31.

IAMAMOTO. M. V.; CARVALHO, R. Relações Sociais e o Serviço Social no Brasil. 39. ed. São Paulo: Cortez, 2013.

IANNI, O. O ciclo da Revolução Burguesa. Petrópolis: Editora Vozes, 1984.

IMBIRIBA, B. Desenvolvimento em Marx e na teoria econômica - a crítica negativa do desenvolvimento capitalista. Niterói: EDUFF, 2016.

MARRO. K. I. O que a universidade pode aprender quando coloca seus pés em um acampamento sem terra? In: ABRAMIDES, M.B.C e DURIGUETTO' M.L (orgs) Movimentos Sociais e Serviço Social: uma relação necessária. São Paulo: Cortez, 2014, p.194-278 .

MARX, K. Contribuição à Crítica da Economia Política. São Paulo: Expressão Popular, 2007.

MATTOS M. B. Movimentos sociais: aproximações teóricas e exemplo histórico forte. In: PESTANA, M. M., COSTA, R. M. C., OLIVEIRA, T. B. (orgs.) Subalternos em movimento: mobilização e enfrentamento a dominação no Brasil. Rio de Janeiro: Consequência Editora, 2017, p.33-52. 
NETTO J. P. A construção do projeto ético-político do Serviço Social frente à crise contemporânea. In: CFESS/ABEPSS; CEAD/UnB (Org.). Crise contemporânea, questão social e Serviço Social. Módulo 1, Capacitação em Serviço Social e política social. Brasília: CEAD/UnB, 1999, p. 91-111.

NETTTO, L. S. O conservadorismo clássico: elementos de caracterização e crítica. São Paulo: Cortez, 2011.

RAICHELIS, R. O assistente social como trabalhador assalariado: desafios frente a violação d seus direitos. Revista Serviço Social e Sociedade, São Paulo, n. 107, jul./set. 2011, p. 420-437.

SANTOS, R. B. Movimentos Sociais Urbanos. São Paulo: Editora Unesp, 2008. 